\title{
Loss of Metabotropic Glutamate Receptor-Dependent Long- Term Depression via Downregulation of mGluR5 after Status Epilepticus
}

\author{
Timo Kirschstein, ${ }^{1,3 *}$ Michel Bauer, ${ }^{1 \star}$ Lorenz Müller, ${ }^{3}$ Christiane Rüschenschmidt, ${ }^{1}$ Margit Reitze, ${ }^{1}$ Albert J. Becker, ${ }^{2}$ \\ Susanne Schoch, ${ }^{2}$ and Heinz Beck ${ }^{1}$ \\ Departments of ${ }^{1}$ Epileptology and ${ }^{2}$ Neuropathology, University of Bonn, D-53105 Bonn, Germany, and ${ }^{3}$ Department of Physiology, University of Rostock, \\ D-18057 Rostock, Germany
}

\begin{abstract}
Synaptic plasticity is thought to be a key mechanism of information storage in the CNS. Different forms of synaptic long-term potentiation have been shown to be impaired in neurological disorders. Here, we show that metabotropic glutamate receptor (mGluR)-dependent long-term depression (LTD), but not NMDA receptor-dependent LTD at Schaffer collateral-CA1 synapses, is profoundly impaired after status epilepticus. Brief application of the group I mGluR agonist $(R, S)$-3,5-dihydroxyphenylglycine ( $100 \mu \mathrm{m} ; 5 \mathrm{~min})$ induced mGluR LTD in control, but not in pilocarpine-treated rats. Experiments in the presence of selective inhibitors of either mGluR5 [2-methyl-6(phenylethynyl)-pyridine] or mGluR1 [7-(hydroxyimino)cyclopropachromen-carboxylate ethyl ester and $(S)$ - $(+)$ - $\alpha$-amino-4-carboxy2-methylbenzeneacetic acid] demonstrate that loss of mGluR LTD is most likely attributable to a loss of mGluR5 function. Quantitative real-time reverse transcription PCR revealed a specific downregulation of mGluR5 mRNA, but not of mGluR1 mRNA in the CA1 region. Furthermore, we detected a strong reduction in mGluR5 protein expression by immunofluorescence and quantitative immunoblotting. Additionally, the scaffolding protein Homer that mediates coupling of mGluR5 to downstream signaling cascades was downregulated. Thus, we conclude that the reduction of mGluR LTD after pilocarpine-induced status epilepticus is the result of the subtype-specific downregulation of mGluR5 and associated downstream signaling components.
\end{abstract}

Key words: CA1; Schaffer collateral; metabotropic glutamate receptor; DHPG; long-term depression; metaplasticity

\section{Introduction}

The potential to exhibit long-lasting activity-dependent changes in synaptic transmission is a key feature of most synapses in the CNS. At hippocampal synapses, low-frequency stimulation (LFS) readily elicits a long-lasting depression of synaptic efficacy, termed long-term depression (LTD). Hippocampal LTD has been of particular interest because of the well established role of the hippocampus in information storage and retrieval. Indeed, it appears that induction of hippocampal LTD is associated with acquisition of novel information (Braunewell and ManahanVaughan, 2001). An additional intriguing feature of hippocampal LTD is that it is modulated by the behavioral state of the animal. For instance, stress powerfully influences the levels of LTD that can be obtained (Xu et al., 1997; Yang et al., 2005). Thus, LTD, as well as long-term potentiation (LTP) (Bliss and Collingridge, 1993) have been suggested to be key mechanisms

\footnotetext{
Received Sept. 1, 2005; revised May 31, 2007; accepted May 31, 2007.

This work was supported by the Sonderforschungsbereich Transregio 3 of the Deutsche Forschungsgemeinschaft (DFG) (A.J.B., S.S., H.B.), the Emmy Noether Program of the DFG (S.S.), and a Bundesministerium für Bildung und Forschung Schwerpunktprogramm (H.B., T.K.) and Forschungsförderung an der Universität Bonn. We thank Jian Chen for performing the quantitative real-time RT-PCR.

*T.K. and M.B. contributed equally to this work.

Correspondence should be addressed to Dr. Timo Kirschstein, Department of Physiology, University of Rostock, Gertrudenstrasse 9, D-18055 Rostock, Germany. E-mail: timo.kirschstein@uni-rostock.de.

DOI:10.1523/JNEUROSCI.4572-06.2007

Copyright $\odot 2007$ Society for Neuroscience $\quad$ 0270-6474/07/277696-09\$15.00/0
}

underlying information storage in the CNS (Abraham and Bear, 1996; Braunewell and Manahan-Vaughan, 2001).

In the CA1 region, low-frequency stimulation readily elicits a form of LTD that requires the activation of postsynaptic NMDA receptors (NMDARs) during induction (Nicoll et al., 1998). At the same synapses, a distinct form of LTD can be observed in the absence of functional NMDARs that requires the activation of metabotropic glutamate receptors (mGluRs) and relies on different expression mechanisms (Oliet et al., 1997). In the CA1 region, mGluR LTD can be readily induced by transient activation of postsynaptic group I $m$ GluRs with a pharmacological agonist [for instance $(R, S)$-3,5-dihydroxyphenylglycine (DHPG)] (Palmer et al., 1997; Fitzjohn et al., 2001). During certain types of lowfrequency activity, activation of mGluRs by endogenously released glutamate also appears to result in mGluR-dependent, NMDAR-independent LTD with similar characteristics (Oliet et al., 1997; Kemp and Bashir, 1999; Huber et al., 2000). Its mechanism of expression is thought to involve a modification of the presynaptic release machinery downstream of presynaptic $\mathrm{Ca}^{2+}$ influx (Fitzjohn et al., 2001; Faas et al., 2002; Zakharenko et al., 2002), in addition to postsynaptic mechanisms culminating in a reduction in synaptic AMPA receptors (Huber et al., 2000; Snyder et al., 2001; Xiao et al., 2001; Nosyreva and Huber, 2005). These results point to a coexistence of multiple forms of mechanistically distinct forms of LTD within the hippocampal CA1 region.

In recent years, considerable interest has focused on impair- 
ment of specific forms of synaptic plasticity in diverse CNS disorders such as Alzheimer's disease (Oddo et al., 2003), epilepsy (Beck et al., 2000), or neurofibromatosis (Costa et al., 2001). In many instances, a reduction of the potential of synapses to exhibit LTP was associated with deficits in specific cognitive functions. These findings are consistent with the view that impaired synaptic plasticity underlies cognitive dysfunction in some of these disorders. In contrast to impaired LTP, however, disease-related changes in the potential to exhibit LTD have so far received scant attention. In the present study, we show that mGluR LTD in the CA1 region is profoundly reduced, most probably because of a selective downregulation of mGluR5, as well as the scaffolding protein Homer.

\section{Materials and Methods}

Pilocarpine-induced status epilepticus. A sustained status epilepticus was induced in young male Wistar rats ( $\sim 30 \mathrm{~d}, 140-150 \mathrm{~g}$; Charles River, Sulzfeld, Germany). First, all animals received methylscopolamine nitrate $(1 \mathrm{mg} / \mathrm{kg}$, i.p./s.c.) to reduce peripheral cholinergic effects. After 30 min they received pilocarpine hydrochloride (experimental group; 340 $\mathrm{mg} / \mathrm{kg}$, i.p./s.c.). If status epilepticus had not developed within $60 \mathrm{~min}$, animals were reinjected ( $170 \mathrm{mg} / \mathrm{kg}$, i.p./s.c.). status epilepticus was terminated $40 \mathrm{~min}$ after onset by injection of diazepam $(4-10 \mathrm{mg} / \mathrm{kg}$, i.p./ s.c.). Sham-control animals were treated in an identical manner, but were injected with saline instead of pilocarpine. The rats were tended and fed with glucose solution for $1 \mathrm{~d}$ and kept in separate cages. After status epilepticus, animals were video monitored for occurrence of spontaneous seizures, starting $\sim 14 \mathrm{~d}$ after pilocarpine treatment. The vast majority of rats that had experienced status epilepticus developed chronic, spontaneous seizures. Only rats that had experienced at least three generalized stage 5 seizures documented with video monitoring were used for electrophysiological experiments, which were conducted $4-10$ weeks after status epilepticus.

Hippocampal slice preparation and maintenance. Animals were deeply anesthetized with diethyl ether, decapitated, and the brains were dissected out quickly. Transverse hippocampal slices $(400 \mu \mathrm{m})$ were prepared using a vibratome (1000S, Leica, Wetzlar, Germany; Integraslice, Campden Instruments, Loughborough, UK) in ice-cold dissection fluid containing (in mM) $125 \mathrm{NaCl}, 25 \mathrm{NaHCO}_{3}, 3 \mathrm{KCl}, 1.25 \mathrm{NaH}_{2} \mathrm{PO}_{4}, 0.2$ $\mathrm{CaCl}_{2}, 5 \mathrm{MgSO}_{4}$, and $13 \mathrm{D}$-glucose. All procedures were performed according to the guidelines laid down by the Animal Care and Use Committee at the Universities of Bonn or Rostock. Slices were transferred into an interface chamber and superfused $(1.8-2.0 \mathrm{ml} / \mathrm{min})$ with bath solution containing (in mM) $125 \mathrm{NaCl}, 26 \mathrm{NaHCO}_{3}, 3 \mathrm{KCl}, 1.25 \mathrm{NaH}_{2} \mathrm{PO}_{4}$, $2.5 \mathrm{CaCl}_{2}, 1.3 \mathrm{MgCl}_{2}$, and $13 \mathrm{D}$-glucose and bubbled with carbogen $(95 \%$ $\mathrm{O}_{2}, 5 \% \mathrm{CO}_{2}$ ) to maintain the $\mathrm{pH}$ of 7.4. Osmolality was adjusted to $306-308 \mathrm{mOsm} / \mathrm{kg}$ with sucrose.

Stimulation and recording. Schaffer collateral fibers were stimulated via a bipolar platinum wire electrode $(0.1-0.3 \mathrm{~mA}, 100 \mu \mathrm{s}$, paired-pulse stimulation, $40 \mathrm{~ms}$ apart, every $30 \mathrm{~s}$ ) placed in the stratum radiatum of the CA1 region. Field EPSPs (fEPSPs) were recorded in the CA1 stratum radiatum at $35^{\circ} \mathrm{C}$ via a borosilicate glass pipette $(4 \mathrm{M} \Omega)$ filled with bath solution. The baseline stimulation strength was adjusted to yield EPSPs of half maximal amplitude. The stimulation paradigms to induce synaptic depression were as follows: paired-pulse (PP) LFS was performed at $1 \mathrm{~Hz}$ with 900 paired stimuli (interpulse interval, $50 \mathrm{~ms}$ ). LFS consisted of 900 single stimuli at $1 \mathrm{~Hz}$, at double the stimulus intensity used for baseline stimulation. Analog data were digitized and stored for off-line analysis (Digidata 1322, pCLAMP8, Molecular Devices, Foster City, CA; Power1401, Signal2, Cambridge Electronic Design, Cambridge, UK). The glutamate receptor ligands $(R, S)$-3,5-DHPG, 2-methyl-6-(phenylethynyl)-pyridine (MPEP), 7-(hydroxyimino)cyclopropa[b]chromen-carboxylate ethyl ester (CPCCOEt), $(S)-(+)-\alpha-$ amino-4-carboxy-2-methylbenzeneacetic acid (LY367385), and D-(-)-2amino-5-phosphopentoate (D-AP5) were obtained from Tocris (Bristol, UK). All other chemicals were purchased from Sigma (St. Louis, MO).

To assess the effects of DHPG, PP LFS, or LFS, the fEPSP slope, which was measured as the maximal slope of its falling phase, was analyzed. Data points in the graphs showing the time courses of the DHPG, PP LFS, or LFS experiments represent an average of two subsequent fEPSP slope values. Thus, sample traces also represent an average trace of two subsequent individual traces. In addition, for each individual experiment, the acute depression was measured as the minimal slope during the first five traces after treatment, and LTD was measured as the average slope during the last five traces at the end of the experiment. The paired-pulse facilitation (PPF) was measured as the ratio of the second fEPSP slope to the first fEPSP slope. All data are expressed as the mean \pm SEM. Statistical comparisons were performed using two-tailed Student's test with a $p$ value $<0.05$ being considered statistically significant. In the figures, diamonds denote significant changes in fEPSP slope compared with the pre-DHPG or pre-LFS/PP LFS baseline. All other significant differences are indicated by asterisks.

Quantitative real-time RT-PCR. For mRNA isolation, $600 \mu \mathrm{m}$ horizontal slices were cut in ice-cold PBS, pH 7.4, (Biochrom, Berlin, Germany) and the CA1 region was microdissected out under a binocular in ice-cold PBS. Tissue specimens were immediately frozen in liquid nitrogen for mRNA isolation. mRNA was isolated using the Dynabeads mRNA Direct Micro Kit (Dynal, Lake Success, NY). Quantification of rat mGluR1 and mGluR5 transcripts was performed by semiquantitative real-time reverse transcription (RT)-PCR (PRISM 7700 SDS; PE Biosystems, Foster City, CA) by using specific primers designed by Primer Express software (PE Biosystems) for rat synaptophysin $\left[5^{\prime}-\right.$ TCAGGACTCAACACCTCAGTGG-3' as forward primer (FP), $5^{\prime}$ AACACGAACCATAAGTTGCCAA- $3^{\prime}$ as reverse primer (RP), and 6-carboxy-fluorescein (FAM)-5'-TTTGGCTTCCTGAACCTGGTGCTCTG-3'-6-carboxytetramethyl-rhodamine (TAMRA) as hybridization probe (HP) at 300, 300, and $100 \mathrm{~nm}$, respectively], mGluR1 (5' GGGCAGGGAATGCCAATT-3' as FP, 5'-GGCGCCTGTCTTCCACC- $3^{\prime}$ as RP, and FAM-5'-GCAAGTCTGTGTCATGG-TCTGAACC- $3^{\prime}$ TAMRA as HP at 50, 300, and $100 \mathrm{nM}$, respectively), and mGluR5 (5'CTCCTGGCCCACTGACGA-3' as FP, 5' -GGTCACCCCAGCGAAGATAC- $3^{\prime}$ as RP, and FAM-5'-GACAGGCTGTGACTTGATCCCAGTCC$3^{\prime}$-TAMRA as HP at 50,300, and $100 \mathrm{nM}$, respectively). We performed relative quantification of starting mRNA copy numbers according to the $\Delta \Delta C_{\mathrm{t}}$ method, as described in detail previously (Riazanski et al., 2001). Synaptophysin was used as endogenous reference gene because it lacks significant expression changes after pilocarpine-induced status epilepticus (Chen et al., 2001). The TaqMan EZ RT-PCR Kit (PE Biosystems) was used to perform single-tube, single-enzyme RT-PCRs in a total reaction volume of $12.5 \mu \mathrm{l}$. Relative quantification started from $0.02 \mathrm{ng}$ of mRNA with $5 \mathrm{~mm} \mathrm{Mn}(\mathrm{OAc})_{2}$. Cycling conditions were $50^{\circ} \mathrm{C}(2 \mathrm{~min})$, $60^{\circ} \mathrm{C}(20 \mathrm{~min})$ for RT step, followed by $95^{\circ} \mathrm{C}(5 \mathrm{~min})$, and a two-step PCR with 60 cycles of $94^{\circ} \mathrm{C}(15 \mathrm{~s})$ and $59^{\circ} \mathrm{C}(1 \mathrm{~min})$. For statistical analysis, fluorescence data were collected.

Immunohistochemistry. Animals were deeply anesthetized with isoflurane (Abbott, Wiesbaden, Germany), and $600 \mu \mathrm{m}$ slices were prepared as described above and embedded in Tissue-Tek (Sakura, McGaw Park, IL). Twelve micrometer sections were cut on a cryostat, fixed in $4 \%$ paraformaldehyde ( $5 \mathrm{~min}$ ), thoroughly washed with PBS, heated in citrate buffer $(0.01 \mathrm{M}, \mathrm{pH} 6.0)$ in the microwave for $3 \mathrm{~min}$, and washed again in PBS with $0.1 \%$ Triton $\mathrm{X}-100$ (PBS-T). After preincubation with $0.4 \%$ bovine serum albumin (BSA) in PBS-T for $90 \mathrm{~min}$ at room temperature, the primary antibody (mGluR5, 1:200, in PBS-T with $0.1 \% \mathrm{NaN}_{3}$ and $2 \%$ BSA; Millipore, Lake Placid, NY) was applied for $16-24 \mathrm{~h}$ at $4^{\circ} \mathrm{C}$. Slices were washed with $\mathrm{PBS}$ and subsequently incubated with the secondary antibody (Cy3, 1:200, in PBS-T with $0.1 \% \mathrm{NaN}_{3}$ and $2 \%$ BSA; Jackson ImmunoResearch, West Grove, PA) for $2 \mathrm{~h}$. For staining of the nuclei, 4,6-diamidino-2-phenylindole (DAPI) (1:1000; Sigma) was coapplied. After washing with PBS, slices were preserved in Vectashield (Vector Laboratories, Burlingame, CA). For cell counts in the CA1 region, unfixed $12 \mu \mathrm{m}$ cryostat sections were cut and subjected to hematoxylin and eosin (HE) staining. One section per animal of sham-injected and of pilocarpine-treated rats ( $n=6$ in both groups) was then photographed at an upright microscope (Axioskop; Zeiss, Leipzig, Germany). Cell numbers within an equally sized region of interest within the CA1 stratum pyramidale were manually quantified using the cell-counter plug-in of ImageJ (National Institutes of Health, Bethesda, MD).

Protein fractionation. The CA1 region was microdissected from vi- 
bratome slices $(600 \mu \mathrm{m})$, and samples from individual animals were pooled. The tissue was homogenized on ice for $10 \mathrm{~s}$ with a labsonic2000 (Braun, Melsungen, Germany) in buffer A (10 $\mu \mathrm{l} / \mathrm{mg}$ tissue) containing (in $\mathrm{mm}$ ) $10 \mathrm{NaCl}$, 25 HEPES, pH 7.5, 2 EDTA, and $1 \mathrm{mg} / \mathrm{ml} \mathrm{4-(2-}$ aminoethyl)-benzenesulfonylfluoride (PEFA)block (Roche, Mannheim, Germany). Homogenates were treated with buffer alone or with $2 \%$ Triton X-100 for 10 min on ice and centrifuged for $30 \mathrm{~min}$ at $18.250 \times g$ and $4^{\circ} \mathrm{C}$. The Triton X-100 containing supernatant was collected and the pellet was resuspended in an equal volume of Buffer B containing (in $\mathrm{mm}$ ) $200 \mathrm{NaCl}, 50 \mathrm{HEPES}$ and $1 \mathrm{mg} / \mathrm{ml}$ PEFA-block (Roche). Subsequently, an equal amount of icecold $1 \%$ SDS solution was added dropwise to the solubilized pellet. The homogenate was centrifuged for $10 \mathrm{~min}$ at $8000 \times g$ and $4^{\circ} \mathrm{C}$, and the SDS-soluble fraction was collected. Protein concentrations of the Triton X-100- and SDSsoluble fractions were determined using the ND-1000 (Nanodrop, Wilmington, DE) and samples were stored at $-80^{\circ} \mathrm{C}$.

Western blotting. Loading buffer containing (in mu) 700 Tris- $\mathrm{HCl}, 30 \%$ glycerol, 290 SDS, $0.012 \%$ bromphenol blue, and either $5 \%$ $\beta$-mercaptoethanol, 200 mм DTT, or no reducing agent was added to the protein samples. Samples were denaturated at $65^{\circ} \mathrm{C}$ for $5 \mathrm{~min}$ and resolved on 6 or $12 \%$ polyacrylamide gels. After transfer onto nitrocellulose membranes, the blots were blocked with $5 \%$ nonfat milk in Tris-buffered saline $/ 0.05 \%$ Tween 20 (TBST) for $1 \mathrm{~h}$, and subsequently incubated with primary antibodies (see below) for $1.5 \mathrm{~h}$. After three 5 min washes with TBST, the membranes were incubated in the dark for $45 \mathrm{~min}$ with the appropriate secondary antibody (1:7500) conjugated to IRDye680 or to IRDye800CW (LICOR, Lincoln, NE). The blots were then washed three times $(5 \mathrm{~min})$ with TBST and stored protected from light in TBST. Protein bands were visualized using the Odyssey Infrared Imaging System (LI-COR). Primary antibodies used were a monoclonal anti- $\beta$-actin (8226) antibody (1:30,000; Abcam, Cambridge, UK), a rabbit polyclonal anti-mGluR5 (06-451) antibody (1:2500; Millipore), a rabbit polyclonal anti-Homer (H-342) antibody (1:2500; Santa Cruz Biotechnology, Santa Cruz, CA), and a goat polyclonal anti-Homer la (M-13) antibody (1: 2500; Santa Cruz Biotechnology). Immunoblots were quantified using the AIDA software program (German Resource Center for Genomics, Berlin, Germany). All data are expressed as the mean \pm SEM. Statistical analysis was performed using a two-tailed Student's test with a $p$ value $<0.05$ being considered statistically significant.

\section{Results}

Reduced NMDAR-independent synaptic depression in the CA1 region after status epilepticus

We first addressed the question how different forms of synaptic LTD induced by LFS of Schaffer collaterals are altered after status epilepticus. We examined NMDAR-independent synaptic plasticity induced by application of PP LFS (900 paired-pulses with an interstimulus interval of $50 \mathrm{~ms}$, applied at $1 \mathrm{~Hz}$ ) in the presence of D-AP5 $(50 \mu \mathrm{M})$. In control rats, PP LFS only caused a transient depression of CA1 field potential slope to $69 \pm 4 \%(n=$ $7 ; p<0.01$ ) (Fig. 1A, C, empty symbols/bars, diamonds indicate significant changes vs pre-LFS baseline) without significant longterm changes after $60 \min (93 \pm 4 \%, n=7)$, as described previously in experiments using a similar $\mathrm{Ca}^{2+} / \mathrm{Mg}^{2+}$ ratio (Oliet et
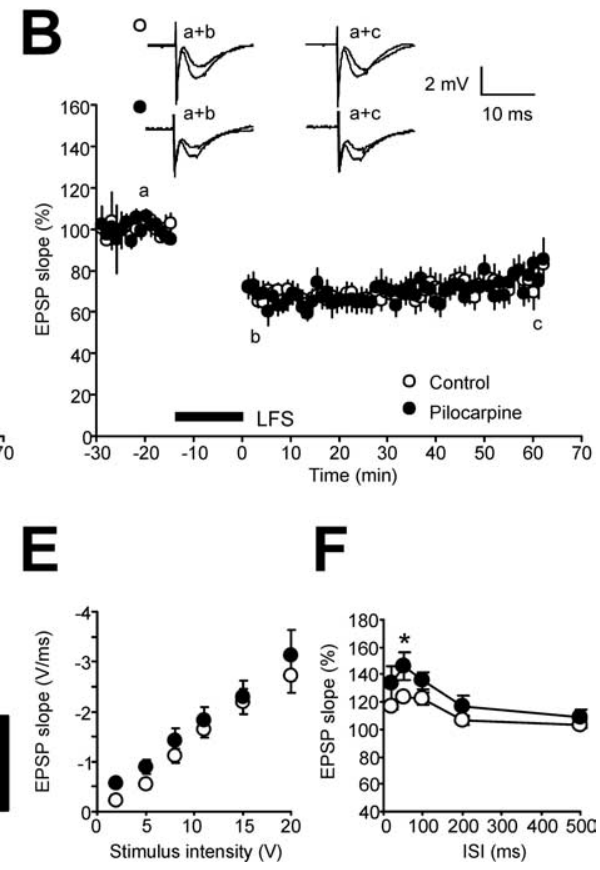

Figure 1. Reduced NMDAR-independent synaptic depression in the CA1 region after status epilepticus. $\boldsymbol{A}$, The time course of CA1 field EPSP slopes after PP LFS (1 Hz, 900 paired pulses, interstimulus interval $50 \mathrm{~ms}$ ) in the presence of the NMDAR blocker D-AP5 (50 $\mu \mathrm{m})$ reveals a significant difference between controls (open circles) and pilocarpine-treated rats (closed circles). (average of two subsequent traces) are taken at the time points indicated by lowercase letters. $\boldsymbol{B}$, The

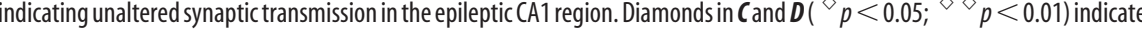
significant differences compared with pre-LFS baseline. Other significant changes are indicated by asterisks $\left({ }^{*} p<0.05\right.$; ${ }^{* *} p<$ 0.01). $\boldsymbol{F}$, The paired-pulse ratio shows an enhanced paired-pulse facilitation of the CA1 field EPSP peak at the interstimulus interval (ISI) of $50 \mathrm{~ms}$ (asterisk). Error bars indicate SEM.

al., 1997). In pilocarpine-treated rats, however, the initial depression was obliterated $(99 \pm 6 \%$ ) (for summary, see Fig. $1 C$, asterisks and black symbols/bars indicate $p<0.01$ vs controls). Moreover, fEPSPs were modestly potentiated rather than depressed 60 min after PP LFS (121 $\pm 8 \% ; n=5$ ) (Fig. $1 A, C)$. Although long-term changes in synaptic transmission were not significant when compared with the pre-LFS baseline, we did observe a significant difference in the long-term changes of synaptic transmission when comparing control and pilocarpine-treated rats (Fig. $1 C$, asterisks indicate $p<0.01$ ).

In addition to NMDAR-independent LFS-induced changes in synaptic transmission, we also examined NMDAR-dependent LTD (Fig. $1 B$ ). We induced LTD in the absence of the NMDAR blocker D-AP5 using a standard LFS protocol consisting of 900 pulses for $15 \mathrm{~min}$ at double stimulus intensity. With this LFS protocol, equivalent levels of LTD were achieved in both groups (Fig. $1 B$ ). As summarized in Figure $1 D$ (right), LFS caused significant post-tetanic depression in both control and pilocarpinetreated rats $(63 \pm 3 \%$ and $65 \pm 6 \%$, respectively) as well as significant LTD (75 $\pm 8 \%$ and $78 \pm 5 \%$, respectively). An examination of input-output curves showed no evidence for significant differences in baseline synaptic transmission between controls $(n=11)$ (Fig. $1 E$, open circles) and pilocarpine-treated animals $(n=10)$ (Fig. $1 E$, closed circles). Double-pulse experiments revealed that the paired-pulse ratio (see Materials and Methods) was significantly different only at a single interpulse 
A
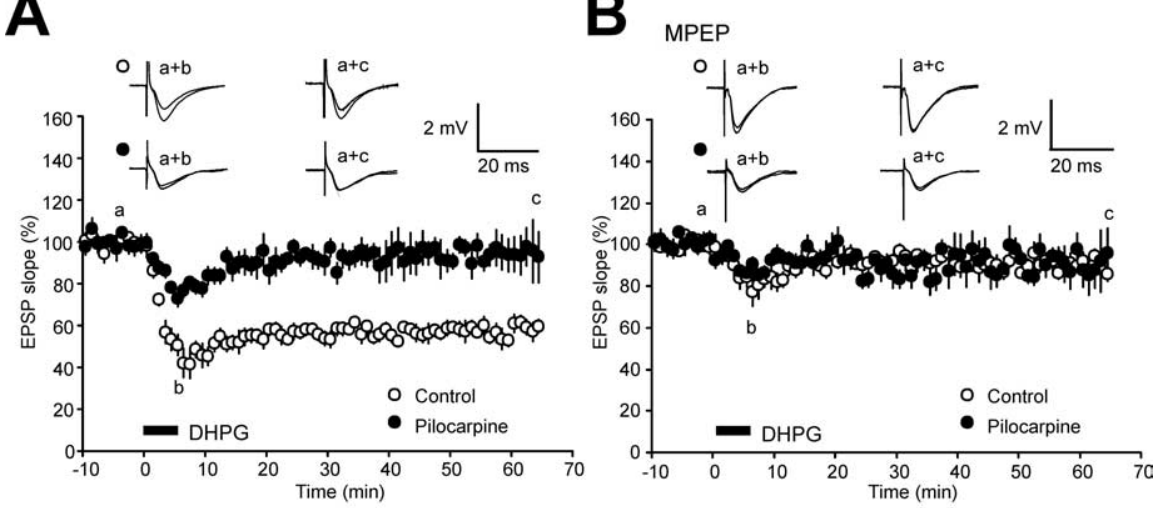

C
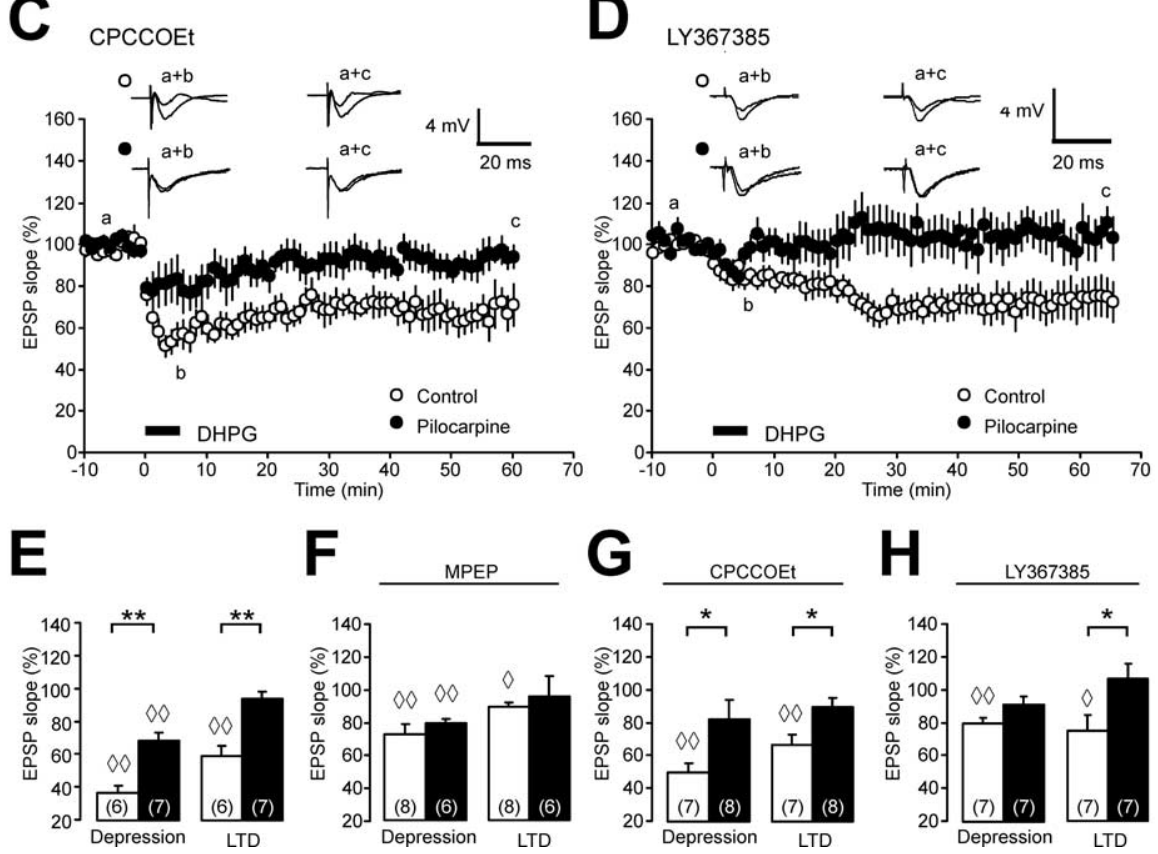

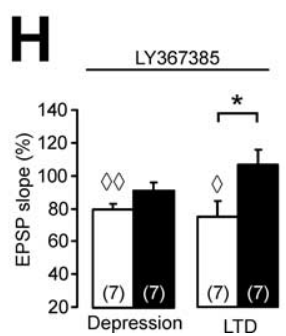

Figure 2. mGluR LTD is impaired after status epilepticus. $A$, The time course of CA1 field EPSP slopes after brief application of DHPG (100 $\mu \mathrm{m}, 5 \mathrm{~min}$ ) shows a significant difference between controls (open circles) and pilocarpine-treated rats (closed circles). Representative field EPSPs (average of two subsequent traces) are taken at the time-points indicated by lowercase letters. $\boldsymbol{B}$, The time course of CA1 field EPSP slopes after brief application of DHPG (100 $\mu \mathrm{M}, 5 \mathrm{~min})$ in the presence of the $\mathrm{mGluR5}$ blocker MPEP $(10 \mu \mathrm{M})$ no longer shows a difference between controls (open circles) and pilocarpine-treated rats (closed circles). C, D, The time course of CA1 field EPSP slopes after brief application of DHPG (100 $\mu \mathrm{m}, 5 \mathrm{~min})$ in the presence of the $\mathrm{mGluR} 1$ blockers CPCCOEt (10 $\mu \mathrm{M} ; \mathrm{C})$ or $\mathrm{LY} 367385(100 \mu \mathrm{m} ; \boldsymbol{D})$ reveals a difference between controls (open circles) and pilocarpine-treated rats (closed circles). $\boldsymbol{E}-\boldsymbol{H}$, Bar graphs showing the DHPG-induced acute depression and LTD levels without mGluR antagonists $(\boldsymbol{E})$, and with preincubation of the mGluR antagonists MPEP $(\boldsymbol{F})$, CPCCOEt $(\boldsymbol{G})$, or LY367385 $(\boldsymbol{H})$. Diamonds in $\boldsymbol{E}-\boldsymbol{H}\left({ }^{\diamond} p<0.05 ;{ }^{\diamond} \diamond_{p}<0.01\right)$ indicate significant differences compared with pre-DHPG baseline. Other significant changes are indicated by asterisks $\left({ }^{*} p<\right.$ $\left.0.05 ;{ }^{* *} p<0.01\right)$. Error bars indicate SEM.

interval (50 ms, $146 \pm 7 \%$ in epileptic rats vs $124 \pm 4 \%$ in controls; $n=7$ in each group) (Fig. $1 F$ ). Thus, it appears that chronically epileptic animals neither exhibit large changes in baseline synaptic transmission, nor a general deficit in the capability to express synaptic depression.

\section{Loss of mGluR-induced synaptic depression after status epilepticus}

Because PP LFS-induced, NMDAR-independent synaptic plasticity has been shown to require activation of the group I metabotropic glutamate receptor mGluR5 (Faas et al., 2002) (but see Volk et al., 2006), we examined whether LTD induced by brief application of the group I mGluR agonist $(R, S)-3,5-\mathrm{DHPG} ; 100$ $\mu \mathrm{M}, 5 \mathrm{~min})$ is altered after status epilepticus. As described previ- ously (Palmer et al., 1997; Oliet et al., 1997; Fitzjohn et al., 2001), brief application of DHPG caused an immediate depression of CA1 EPSP slope to $37 \pm 4 \%$ in control animals. After washout of DHPG, a longlasting reduction of EPSPs was observed (mGluR LTD, $60 \pm 6 \%$ of pre-DHPG baseline; $n=6$ ) (Fig. $2 A, E$, empty symbols, diamonds indicate significant changes vs pre-DHPG baseline). The capability for DHPG-induced LTD was dramatically modified after status epilepticus. The initial depression during DHPG application was profoundly reduced (69 \pm $5 \%$ of pre-DHPG baseline; $n=7$ ) and mGluR LTD was abolished $(95 \pm 5 \%$; $n=$ 7) (Fig. $2 A, E$, filled symbols, bars, asterisks indicate $p<0.01$ for both initial depression and LTD for control vs pilocarpinetreated rats). To rule out a role for NMDARs in this form of depression, we performed additional experiments in the presence of D-AP5 $(50 \mu \mathrm{M})$. These experiments revealed a similar reduction in both the initial depression ( $49 \pm 6 \%$ in control animals vs $74 \pm 4 \%$ in pilocarpine-treated animals; $p<0.01$ ) and an obliteration of mGluR LTD after status epilepticus (control animals, $73 \pm 5 \%$; pilocarpine-treated animals, $98 \pm 9 \%$; $n=6$; $p<0.05$ ) (data not shown).

\section{Loss of mGluR5 receptor function underlies loss of mGluR LTD}

We went on to investigate the mechanisms that might underlie the status epilepticusassociated change in DHPG-induced LTD. This form of mGluR LTD is known to require the activation of mGluR5 (Palmer et al., 1997; Fitzjohn et al., 1999; Faas et al., 2002). We therefore hypothesized that a loss of functional mGluR5 might underlie the profound reduction in mGluR LTD in the $\mathrm{CA} 1$ region. To address this question, we pharmacologically blocked mGluR5 during LTD induction using the specific mGluR5 antagonist MPEP (10 $\mu \mathrm{M})$. In control rats, MPEP strongly reduced both the initial depression during DHPG application (to $73 \pm 6 \% ; p<0.01$ vs untreated control slices) and LTD (to $89 \pm 3 \% ; n=8 ; p<0.01$ vs untreated control slices) (Fig. $2 B, E$ ). In contrast, mGluR-induced depression was not further reduced by preapplication of MPEP in pilocarpine-treated rats (fEPSP slope during initial depression, $79 \pm 3 \%$; 60 min after DHPG application, $96 \pm 12 \% ; n=6$ ). As a result, differences between control and pilocarpine-treated rats were no longer apparent (Fig. 2B, F). These results strongly indicate that loss of mGluR5 or impairment of its function underlies the reduction in mGluR LTD.

In contrast, blocking mGluR1 with CPCCOEt $(10 \mu \mathrm{M})$ in control animals did not cause significant changes in both the initial depression and mGluR LTD (depression, $50 \pm 6 \%$; LTD, $67 \pm$ $7 \% ; n=7)$ compared with control slices without CPCCOEt. 
Likewise, blocking mGluR1 did not affect mGluR-induced depression in pilocarpine-treated animals (initial depression, $83 \pm 12 \%$; LTD, $90 \pm 6 \%$; $n=8)$ (Fig. $2 C, G$ ) compared with control experiments. Consequently, a significant difference in both the acute depression and mGluR LTD was maintained between control and pilocarpine-treated rats in the absence of functional mGluR1 receptors $(p<0.05)$ (Fig. 2G, asterisks). Because available evidence suggests that CPCCOEt may not be sufficiently selective (Volk et al., 2006), we repeated these experiments using the newer and more potent mGluR1 antagonist LY367385 (Fig. 2D). Similar to the experiments with CPCCOEt described above, DHPG-induced LTD was reliably induced in controls $(75 \pm 9 \% ; n=7 ; p<$ 0.05 vs pre-DHPG-baseline) (Fig. $2 H$ ), but not in pilocarpine-treated rats $(106 \pm$ $9 \% ; n=7 ; p<0.05$ vs controls) (Fig. $2 H$ ). These results strongly argue that the reduction in mGluR LTD is caused by loss of mGluR5 receptors or receptor function.

\section{Downregulation of mGluR5 after status epilepticus}

Because these results suggest downregulation of mGluR5, but not mGluR1 receptor expression or function, we studied the expression of these two receptor isoforms in the CA1 region using quantitative realtime RT-PCR. We used synaptophysin as a reference gene because it is expressed only in neurons, and because its mRNA does not display differences in abundance per individual neuron in control versus pilocarpine-treated animals (Chen et al., 2001). We found no significant alterations in transcript abundance for mGluR1 (Fig. 3A). In contrast, mGluR5 was expressed at significantly lower levels after status epilepticus (Fig. 3B). The regulation of mGluR5 was not a general feature of postsynaptically expressed ion channel or receptor genes. The levels of sodium channel mRNAs encoding the $\beta_{1}$ and $\beta_{2}$ subunits, as well as the $\mathrm{Na}_{\mathrm{v}} 1.1$ subunit, were not reduced in rats that have experienced status epilepticus (114, 121 , and $130 \%$ of control values, respectively; $n=5$ in controls and $n=6$ in pilocarpine-treated rats).

Next, we studied whether the decrease in mGluR5 transcript translates to a reduction in the corresponding protein levels. We first performed immunohistochemistry with an antibody to mGluR5 on horizontal hippocampal sections from control and pilocarpine-treated rats. These experiments revealed a marked loss of mGluR5 protein in the CA1 stratum radiatum in pilocarpine-treated rats compared with control animals (Fig. $4 A)$. To quantify the loss of mGluR5 protein, we performed quantitative immunoblotting analyses on membrane fractions of microdissected CA1 subregions. The anti-mGluR5 antibody detected a major band of $\sim 130 \mathrm{kDa}$, corresponding to monomeric mGluR5 subunits (Fig. 4B, indicated by C) (Romano et al., 1996).
Two additional, weaker bands of higher molecular weight were detected between 260 and $290 \mathrm{kDa}$ (Fig. 4 B, indicated by A and B) ( $n=4$ and 5 for control and pilocarpine-treated animals, respectively; protein homogenate of CA1 tissue isolated and pooled from one animal was loaded per lane). These most probably correspond to disulfide-linked mGluR5 dimers, as reported previously (Romano et al., 1996, 2001). Indeed, when immunoblots were performed under nonreducing conditions, virtually all of the mGluR5 protein migrated as high molecular mass forms (data not shown). Utilizing actin as an internal standard, we quantified the relative abundance of mGluR5 in the CA1 region of control versus pilocarpine-treated rats. We found a pronounced reduction in mGluR5 expression levels that was highly significant for all three size forms detected (Fig. $4 C$, asterisks) (reductions of $\sim 76, \sim 60$, and $\sim 68 \%$ for the 290,260 , and 130 $\mathrm{kDa}$ forms, respectively). Could these reductions be cause by a loss of CA1 neurons in pilocarpine-treated animals, which is undoubtedly present even after the rather brief status epilepticus in 
A
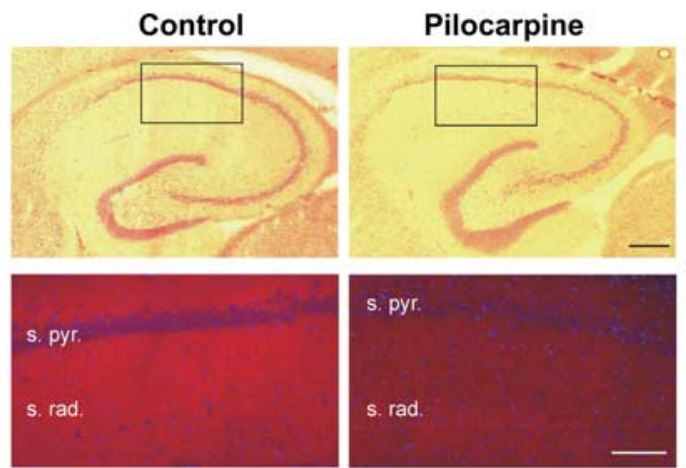

B

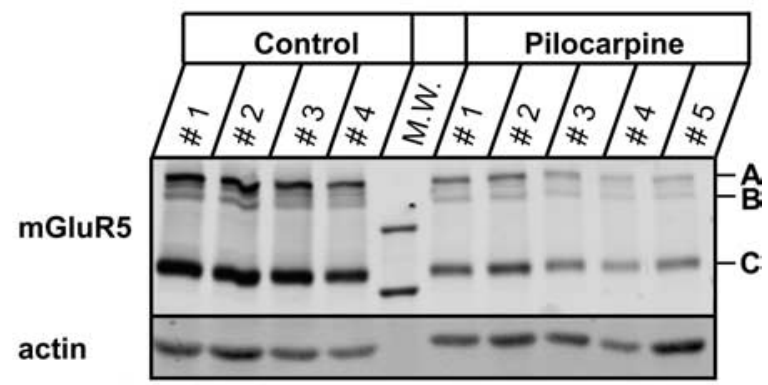

C

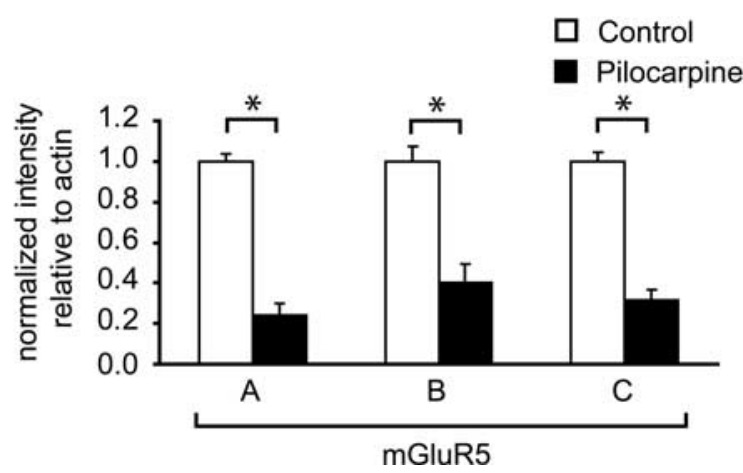

Figure 4. mGluR5 protein is decreased after status epilepticus. $\boldsymbol{A}$, Hippocampal sections of control (left) and pilocarpine-treated (right) animals were stained with HE or probed with an antibody against mGluR5 (red). s. pyr., Stratum pyramidale; s. rad., stratum radiatum. Nuclei (blue) were labeled with DAPI. Scale bars: top, $400 \mu \mathrm{m}$; bottom, $10 \mu \mathrm{m}$. B, mGluR5 membrane fractions isolated from microdissected CA1 subregions. Fractions (see Materials and Methods) were analyzed by SDS-PAGE and immunoblotting with antibodies to mGluR5 and actin as indicated. The mGluR5 antibody recognized three specific bands: one corresponding to mGluR5 monomers at an apparent molecular mass of $\sim 130 \mathrm{kDa}$ and two weaker bands of higher molecular weight, between 260 and $290 \mathrm{kDa}$, representing mGluR5 dimers (indicated by C, B, and $A$, respectively). (A1 tissue collected from one animal was loaded per lane. $n=4$ and 5 for control and pilocarpine-treated animals, respectively. M.W., Molecular weight marker. C, Relative abundance of the three mGluR5 complexes. Proteins were quantified with the 0 dyssey imaging system. mGluR5 protein levels were normalized to actin protein levels for each lane and expressed as mean \pm SEM $(n=4)$. Significant reductions are indicated by asterisks.

our model? We quantified the loss of neurons in the pyramidal layer of the CA1 region in control and pilocarpine-treated animals, and found that the density of CA1 neurons is reduced by $40.3 \%$ in epileptic animals $[n=6$ control $( \pm 0.11 \%)$ and pilocarpine-treated $( \pm 0.07 \%)$ animals, respectively; $p<0.01 \%]$. Thus, we conclude that cell loss accounts for some, but not all of the loss of mGluR5 protein in the CA1 region.

We next considered whether there might be changes in signaling components downstream of mGluR5. Homer proteins are a family of $>15$ postsynaptic scaffolding molecules that facilitate
A

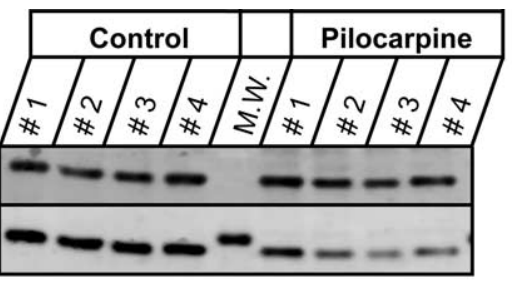

B

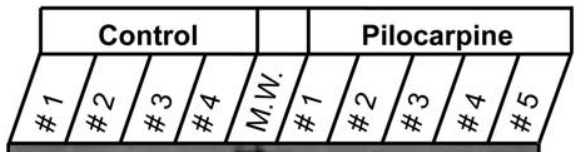

Homer

Homer1a

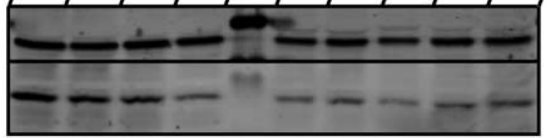

C

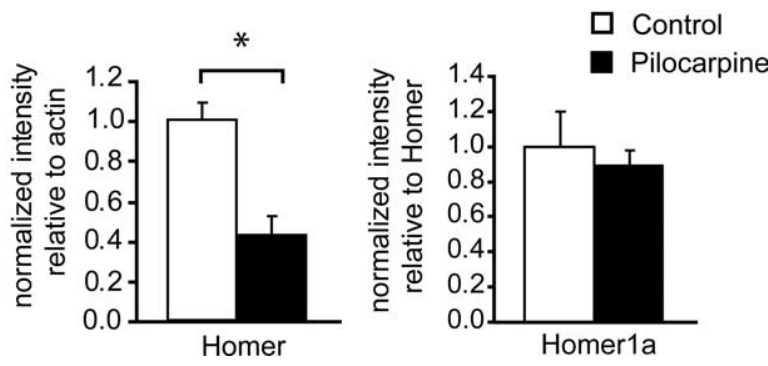

Figure 5. Protein levels of Homer isoforms are reduced after status epilepticus. A, Immunoblots of membrane fractions isolated from microdissected CA1 subregions (see Materials and Methods) probed with an anti-Homer antibody recognizing all Homer isoforms and an antiactin antibody as indicated. CA1 tissue collected and pooled from two animals was loaded per lane. $\boldsymbol{B}$, Immunoblots of membrane fractions isolated from microdissected CA1 subregions probed with an anti-Homer antibody as in $\boldsymbol{A}$, and an isoform-specific anti-Homer1a antibody. CA1 tissue preparations from one animal were loaded per lane. C, Quantification of the abundance of Homer relative to actin (left) reveals a significant downregulation of Homer isoforms migrating at $\sim 47 \mathrm{kDa}$. The relative ratios of long Homer isoforms versus Homer1a (right) were unaltered. Error bars indicate SEM.

the aggregation of specific postsynaptic proteins, and modulate their function (for review, see Duncan et al., 2005). Most Homer isoforms are constitutively expressed, have a molecular mass of $\sim 47 \mathrm{kDa}$, and contain EVH1 domains that bind mGluRs, as well as CC domains that allow homodimerization and heterodimerization. A short Homer isoform (Homerla; $\sim 28 \mathrm{kDa}$ ) lacks the C-terminal CC domain and therefore does not dimerize. This isoform is not constitutively expressed, but is powerfully induced by activity. Long Homer isoforms are known to link mGluR5 activation to intracellular signal transduction, such as the extracellular signal-regulated protein kinase cascade (Yang et al., 2004; Mao et al., 2005), or inositol triphosphate receptor mediated signaling (Sala et al., 2005). We first examined whether the abundance of long Homer isoforms might be altered in protein extracts from the CA1 region of control versus pilocarpine-treated rats. Western blotting with an antibody recognizing all Homer isoforms revealed a prominent band at $47 \mathrm{kDa}$, corresponding to the long isoforms (Fig. $5 A)(n=4$ for the control and pilocarpine groups, protein homogenates collected from two animals were loaded on each lane). When we normalized the abundance of Homer to actin, we found a significant $\sim 57 \%$ reduction in protein levels of long Homer isoforms (Fig. 5C, left, asterisk). Thus, both mGluR5 and long Homer isoforms are downregulated to an extent that is not accounted for by neuronal cell loss.

A short isoform of Homer, Homer la, has been reported to act 
as a dominant negative isoform, and can uncouple mGluR5 from postsynaptic signal transduction cascades (Kammermeier and Worley, 2007). We therefore tested whether the relative abundance of long Homer isoforms versus Homerla might be altered after pilocarpine treatment. Probing immunoblots with antibodies both against Homer and Homerla revealed that the relative ratio of long Homer isoforms versus Homerla was unaltered (Fig. $5 B, C$, right) ( $n=4$ and 5 , respectively; protein homogenates collected from one animal were loaded on each lane).

\section{Discussion}

In the present study, we demonstrate the subtype-specific downregulation of mGluR5-transcript and protein in the CA1 region after pilocarpine-induced status epilepticus. In addition, protein levels of the postsynaptic scaffolding molecule Homer, that mediates downstream signaling of mGluR5, are also decreased. As a consequence, mGluR5-dependent long-term depression is abolished. Thus, an episode of status epilepticus causes a long-term loss in the potential to exhibit NMDA-independent long-term synaptic depression in the CA1 region.

\section{Activity-dependent modulation of mGluR-dependent synaptic plasticity}

The modulation of synaptic plasticity by previous activity has been well established and has been collectively termed metaplasticity (Abraham and Bear, 1996). Application of weak highfrequency stimulation has been shown to cause subsequent inhibition of NMDA-dependent LTP (Huang et al., 1992). Conversely, the induction of NMDAR-dependent LTD is enhanced after different types of priming stimulation (Christie and Abraham, 1992; Holland and Wagner, 1998). Metaplasticity has also been observed for mGluR-dependent LTD in the dentate gyrus. In the medial perforant path, high-frequency stimulation inhibited subsequent mGluR LTD or depotentiation. The induction of this form of metaplasticity was found to be NMDARindependent, but required activation of group I/II mGluRs and protein kinase C (PKC) (Rush et al., 2002; Wu et al., 2004). A qualitatively similar finding was obtained by Zho et al. (2002), who demonstrated that mGluR5 activation becomes ineffective in causing depotentiation during the LTP maintenance phase. Together with our results, these experiments suggest that metaplastic reduction of mGluR LTD may occur via two different mechanisms. The first mechanism is fast in onset and relies on activation of mGluRs and PKC (Rush et al., 2002; Wu et al., 2004). The second mechanism, described here, is likely slower, and inhibits mGluR LTD via a transcriptional downregulation of both mGluR5 and Homer proteins. The decrease in mGluR5 and Homer on the protein level is partly caused by neuronal cell loss, but our quantitative data show that there must be an additional downregulation of both Homer and mGluR5 in surviving neurons. Thus, it is likely that the changes in both mGluR5 and Homer abundance conspire to produce a deficit in mGluR5dependent signaling. Indeed, the downregulation of long Homer isoforms is highly likely to affect mGluR5 dependent signaling, because these Homer isoforms link mGluR5 activation to different intracellular signal transduction cascades (Yang et al., 2004; Mao et al., 2005; Sala et al., 2005). Because the presence of Homerla can uncouple mGluR5 from postsynaptic signal transduction cascades (Kammermeier and Worley, 2007), we also examined whether a relative upregulation of Homerla might account for loss of mGluR5 activity. Our results indicate that there are no changes in the abundance of Homerla relative to long Homer isoforms. Thus, it is unlikely that changes in the Homer/
Homerla stochiometry contribute to the functional changes in mGluR LTD.

Interestingly, our data demonstrate that epilepsy causes loss of mGluR LTD, but does not affect NMDA-dependent synaptic depression in the CA1 region, similar to the intact NMDAdependent LTD in the CA1 region after hippocampal lesions induced by kainic acid injection (Bernard and Wheal, 1996). These findings argue for a differential impairment of NMDAdependent and -independent forms of LTD in the CA1 region. It has been suggested that the preservation of such forms of depression might be of use to decrease excitability in the epileptic hippocampus using low-frequency stimulation (Bernard and Wheal, 1996). Although we did not address this issue, it should be noted that the downregulation of mGluR5 may also have effects on NMDA-dependent forms of LTP, because mGluR 5 has been implicated in NMDA-dependent LTP in the CA1 region ( $\mathrm{Lu}$ et al., 1997; Francesconi et al., 2004). The emerging pattern of changes induced by status epilepticus is further complemented by an elegant study by Doherty and Dingledine (2001), in which the properties of excitatory synapses onto interneurons were examined. This study reported enhanced short-term depression at these synapses, partially mediated by group II mGluRs. These results suggest that excitatory drive onto interneurons, and thereby GABAergic inhibition, is weakened in a use-dependent manner.

\section{Postsynaptic expression of group I mGluRs and induction site of mGluR LTD}

It is well established that group I mGluRs are predominantly expressed at the postsynaptic membrane of normal CA1 neurons, with little expression in presynaptic terminals in adult rodents (Romano et al., 1995; Luján et al., 1996; Shigemoto et al., 1997). Available evidence suggests that of the two group I mGluRs, mGluR5 is responsible for mediating LTD induced by application of DHPG (Huber et al., 2001; Faas et al., 2002; Huang et al., 2004) (but see Volk et al., 2006) as well as by PP LFS (Faas et al., 2002). In addition to the anatomical localization of mGluR5 at postsynaptic sites, the importance of postsynaptic mechanisms in the induction and expression of mGluR LTD is supported by experiments using postsynaptic injection of G-protein inhibitors (Watabe et al., 2002; Huang et al., 2004), or endocytosis and protein synthesis inhibitors that prevent glutamate receptor internalization (Snyder et al., 2001; Xiao et al., 2001), as well as experiments assessing changes in presynaptic release directly (Zhang et al., 2006). Intriguingly, these mechanisms may be different in neonatal hippocampus, with mGluR LTD relying on large presynaptic changes (Nosyreva and Huber, 2005). It should be noted that we also observed changes in PPF after application of DHPG, similar to observations of Nosyreva and Huber (2005) for DHPG-induced depression in older animals. These changes cannot, however, by themselves be taken as evidence of a presynaptic process (Poncer and Malinow, 2001). Together, these data largely support a postsynaptic induction and expression mechanism for mGluR LTD in adult animals. Thus, we believe that the reduction of postsynaptic mGluR5 mRNA and protein in CA1 neurons, together with the decrease in Homer protein, is the most parsimonious explanation for the loss of mGluR LTD.

\section{Role of group I mGluRs in temporal lobe epilepsy}

Group I mGluRs have been previously investigated in other models of temporal lobe epilepsy (TLE), as well as in human epilepsy. In qualitative agreement with our study, a transient downregulation of mGluR5, but not mGluR1-mRNA was observed in the kindling model of epilepsy, which subsequently $(\sim 1$ month after 
kindling) returned to control levels (Akbar et al., 1996). However, mGluR5 mRNA was not altered at early stages after kainateinduced seizures (Aronica et al., 1997). After pilocarpineinduced status epilepticus, mGluR $1 \alpha$ was initially upregulated, but returned to baseline by day 7, whereas mGluR5 was not analyzed in this model (Tang et al., 2001b). After electrically induced status epilepticus, an upregulation of mGluR5 in astrocytes has been described (Aronica et al., 2000). Thus, considerable differences exist among the present TLE animal models concerning mGluR expression changes. In the human hippocampus, both mGluR1 and mGluR5 were found in all pyramidal neurons (Blümcke et al., 1996; Tang et al., 2001a). In TLE patients, a striking upregulation of mGluR1 expression has been implicated in the pathophysiology of hippocampal hyperexcitability, whereas mGluR5 was unaltered in the dentate gyrus (Blümcke et al., 2000; Tang et al., 2001a).

\section{Functional consequences of impaired mGluR LTD}

What might the functional consequences of a loss of mGluR LTD be in the context of a chronically epileptic brain? First, mGluR LTD is, along with other forms of synaptic plasticity, a potential cellular mechanism that affects learning and memory. In particular, hippocampal LTD appears to be associated with the acquisition of novelty (Braunewell and Manahan-Vaughan, 2001). It is therefore tempting to speculate that impaired synaptic plasticity may underlie specific cognitive deficits incurred during induction of chronic epilepsy. An additional, particularly intriguing issue is suggested by a previous study in which repeated induction of mGluR LTD caused elimination of glutamatergic synapses (Shinoda et al., 2005). Thus, a loss of mGluR LTD may cause an impaired capacity to eliminate synapses in the epileptic brain. Such a mechanism may be potentially important given the pronounced sprouting, and formation of glutamatergic synapses that is a feature of chronic experimental and human epilepsy.

\section{References}

Abraham WC, Bear MF (1996) Metaplasticity: the plasticity of synaptic plasticity. Trends Neurosci 19:126-130.

Akbar MT, Rattray M, Powell JF, Meldrum BS (1996) Altered expression of group I metabotropic glutamate receptors in the hippocampus of amygdala-kindled rats. Mol Brain Res 43:105-116.

Aronica E, van Vliet EA, Mayboroda OA, Troost D, da Silva FH, Gorter JA (2000) Upregulation of metabotropic glutamate receptor subtype mGluR3 and mGluR5 in reactive astrocytes in a rat model of mesial temporal lobe epilepsy. Eur J Neurosci 12:2333-2344.

Aronica EM, Gorter JA, Paupard MC, Grooms SY, Bennett MV, Zukin RS (1997) Status epilepticus-induced alterations in metabotropic glutamate receptor expression in young and adult rats. J Neurosci 17:8588-8595.

Beck H, Goussakov IV, Lie A, Helmstaedter C, Elger CE (2000) Synaptic plasticity in the human dentate gyrus. J Neurosci 20:7080-7086.

Bernard C, Wheal HV (1996) A role for synaptic and network plasticity in controlling epileptiform activity in CA1 in the kainic acid-lesioned rat hippocampus in vitro. J Physiol (Lond) 495:127-142.

Bliss TV, Collingridge GL (1993) A synaptic model of memory: long-term potentiation in the hippocampus. Nature 361:31-39.

Blümcke I, Behle K, Malitschek B, Kuhn R, Knopfel T, Wolf HK, Wiestler OD (1996) Immunohistochemical distribution of metabotropic glutamate receptor subtypes mGluR1b, mGluR2/3, mGluR4a, and mGluR5 in human hippocampus. Brain Res 736:217-226.

Blümcke I, Becker AJ, Klein C, Scheiwe C, Lie AA, Beck H, Waha A, Friedl MG, Kuhn R, Emson P, Elger C, Wiestler OD (2000) Temporal lobe epilepsy associated up-regulation of metabotropic glutamate receptors: correlated changes in mGluR1 mRNA and protein expression in experimental animals and human patients. J Neuropathol Exp Neurol 59:1-10.

Braunewell KH, Manahan-Vaughan D (2001) Long-term depression: a cellular basis for learning? Rev Neurosci 12:121-140.

Chen J, Sochivko D, Beck H, Marechal D, Wiestler OD, Becker AJ (2001)
Activity-induced expression of common reference genes in individual CNS neurons. Lab Invest 81:913-916.

Christie BR, Abraham WC (1992) Priming of associative long-term depression in the dentate gyrus by theta frequency synaptic activity. Neuron 9:79-84.

Costa RM, Yang T, Huynh DP, Pulst SM, Viskochil DH, Silva AJ, Brannan CI (2001) Learning deficits, but normal development and tumor predisposition, in mice lacking exon 23a of Nf1. Nat Genet 27:399-405.

Doherty J, Dingledine R (2001) Reduced excitatory drive onto interneurons in the dentate gyrus after status epilepticus. J Neurosci 21:2048-2057.

Duncan RS, Hwang SH, Koulen P (2005) Effects of Vesl/Homer proteins on intracellular signalling. Exp Biol Med 230:527-535.

Faas GC, Adwanikar H, Gereau IV RW, Saggau P (2002) Modulation of presynaptic calcium transients by metabotropic glutamate receptor activation: a differential role in acute depression of synaptic transmission and long-term depression. J Neurosci 22:6885-6890.

Fitzjohn SM, Kingston AE, Lodge D, Collingridge GL (1999) DHPGinduced LTD in area CA1 of juvenile rat hippocampus; characterisation and sensitivity to novel mGlu receptor antagonists. Neuropharmacology 38:1577-1583.

Fitzjohn SM, Palmer MJ, May JE, Neeson A, Morris SA, Collingridge GL (2001) A characterisation of long-term depression induced by metabotropic glutamate receptor activation in the rat hippocampus in vitro. J Physiol (Lond) 537:421-430.

Francesconi W, Cammalleri M, Sanna PP (2004) The metabotropic glutamate receptor 5 is necessary for late-phase long-term potentiation in the hippocampal CA1 region. Brain Res 1022:12-18.

Holland LL, Wagner JJ (1998) Primed facilitation of homosynaptic longterm depression and depotentiation in rat hippocampus. J Neurosci 18:887-894.

Huang CC, You JL, Wu MY, Hsu KS (2004) Rap1-induced p38 mitogenactivated protein kinase activation facilitates AMPA receptor trafficking via the GDI-Rab5 complex. Potential role in (S)-3,5-dihydroxyphenylglyceneinduced long term depression. J Biol Chem 279:12286-12292.

Huang YY, Colino A, Selig DK, Malenka RC (1992) The influence of prior synaptic activity on the induction of long-term potentiation. Science 255:730-733.

Huber KM, Kayser MS, Bear MF (2000) Role for rapid dendritic protein synthesis in hippocampal mGluR-dependent long-term depression. Science 288:1254-1257.

Huber KM, Roder JC, Bear MF (2001) Chemical induction of mGluR5- and protein synthesis-dependent long-term depression in hippocampal area CA1. J Neurophysiol 86:321-325.

Kammermeier PJ, Worley PF (2007) Homer 1a uncouples metabotropic glutamate receptor 5 from postsynaptic effectors. Proc Natl Acad Sci USA 104:6055-6060.

Kemp N, Bashir ZI (1999) Induction of LTD in the adult hippocampus by the synaptic activation of AMPA/kainate and metabotropic glutamate receptors. Neuropharmacology 38:495-504.

Lu YM, Jia Z, Janus C, Henderson JT, Gerlai R, Wojtowicz JM, Roder JC (1997) Mice lacking metabotropic glutamate receptor 5 show impaired learning and reduced CA1 long-term potentiation (LTP) but normal CA3 LTP. J Neurosci 17:5196-5205.

Luján R, Nusser Z, Roberts JD, Shigemoto R, Somogyi P (1996) Perisynaptic location of metabotropic glutamate receptors mGluR1 and mGluR5 on dendrites and dendritic spines in the rat hippocampus. Eur J Neurosci 8:1488-1500.

Mao L, Yang L, Tank Q, Samdani S, Zhang G, Wang JQ (2005) The scaffold protein Homer1b/c links mGluR5 to extracellular signal-regulated protein kinase cascades in neurons. J Neurosci 25:2741-2752.

Nicoll RA, Oliet SH, Malenka RC (1998) NMDA receptor-dependent and metabotropic glutamate receptor-dependent forms of long-term depression coexist in CA1 hippocampal pyramidal cells. Neurobiol Learn Mem 70:62-72.

Nosyreva ED, Huber KM (2005) Developmental switch in synaptic mechanisms of hippocampal metabotropic glutamate receptor-dependent longterm depression. J Neurosci 25:2992-3001.

Oddo S, Caccamo A, Shepherd JD, Murphy MP, Golde TE, Kayed R, Metherate R, Mattson MP, Akbari Y, LaFerla FM (2003) Triple-transgenic model of Alzheimer's disease with plaques and tangles: intracellular Abeta and synaptic dysfunction. Neuron 39:409-421.

Oliet SH, Malenka RC, Nicoll RA (1997) Two distinct forms of long-term 
depression coexist in CA1 hippocampal pyramidal cells. Neuron 18:969-982.

Palmer MJ, Irving AJ, Seabrook GR, Jane DE, Collingridge GL (1997) The group I mGlu receptor agonist DHPG induces a novel form of LTD in the CA1 region of the hippocampus. Neuropharmacology 36:1517-1532.

Poncer JC, Malinow R (2001) Postsynaptic conversion of silent synapses during LTP affects synaptic gain and transmission dynamics. Nat Neurosci 4:989-996.

Riazanski V, Becker A, Chen J, Sochivko D, Lie A, Wiestler OD, Elger CE, Beck $\mathrm{H}$ (2001) Functional and molecular analysis of transient voltagedependent $\mathrm{K}^{+}$currents in rat hippocampal granule cells. J Physiol (Lond) 537:391-406.

Romano C, Sesma MA, McDonald CT, O’Malley K, Van den Pol AN, Olney JW (1995) Distribution of metabotropic glutamate receptor mGluR5 immunoreactivity in rat brain. J Comp Neurol 355:455-469.

Romano C, Yang WL, O’Malley KL (1996) MgluR5 is a disulfide-linked dimer. J Biol Chem 271:28612-28616.

Romano C, Miller JK, Hyrc K, Diranian S, Mennerick S, Takeuchi Y, Goldberg MP, O'Malley KL (2001) Covalent and noncovalent interactions mediate mGluR5 dimerization. Mol Pharmacol 59:46-53.

Rush AM, Wu J, Rowan MJ, Anwyl R (2002) Group I metabotropic glutamate receptor (mGluR)-dependent long-term depression mediated via p38 mitogen-activated protein kinase is inhibited by previous highfrequency stimulation and activation of mGluRs and protein kinase $\mathrm{C}$ in the rat dentate gyrus in vitro. J Neurosci 22:6121-6128.

Sala C, Roussignol G, Meldolesi J, Fagni L (2005) Key role of the postsynaptic density scaffold proteins Shank and Homer in the functional architecture of $\mathrm{Ca}^{2+}$ homeostasis at dendritic spines in hippocampal neurons. J Neurosci 25:4587-4592.

Shigemoto R, Kinoshita A, Wada E, Nomura S, Ohishi H, Takada M, Flor PJ, Neki A, Abe T, Nakanishi S, Mizuno N (1997) Differential presynaptic localization of metabotropic glutamate receptor subtypes in the rat hippocampus. J Neurosci 17:7503-7522.

Shinoda Y, Kamikubo Y, Egashira Y, Tominaga-Yoshino K, Ogura A (2005) Repetition of mGluR-dependent LTD causes slowly developing persistent reduction in synaptic strength accompanied by synapse elimination. Brain Res 1042:99-107.

Snyder EM, Philpot BD, Huber KM, Dong X, Fallon JR, Bear MF (2001) Internalization of ionotropic glutamate receptors in response to mGluR activation. Nat Neurosci 4:1079-1085.
Tang FR, Lee WL, Yeo TT (2001a) Expression of the group I metabotropic glutamate receptor in the hippocampus of patients with mesial temporal lobe epilepsy. J Neurocytol 30:403-411.

Tang FR, Lee WL, Yang J, Sim MK, Ling EA (2001b) Expression of metabotropic glutamate receptor lalpha in the hippocampus of rat pilocarpine model of status epilepticus. Epilepsy Res 46:179-189.

Volk LJ, Daly CA, Huber KM (2006) Differential roles for group 1 mGluR subtypes in induction and expression of chemically induced hippocampal long-term depression. J Neurophysiol 95:2427-2438.

Watabe AM, Carlisle HJ, O’Dell TJ (2002) Postsynaptic induction and presynaptic expression of group 1 mGluR-dependent LTD in the hippocampal CA1 region. J Neurophysiol 87:1395-1403.

Wu J, Rowan MJ, Anwyl R (2004) Synaptically stimulated induction of group I metabotropic glutamate receptor-dependent long-term depression and depotentiation is inhibited by prior activation of metabotropic glutamate receptors and protein kinase C. Neuroscience 123:507-514.

Xiao MY, Zhou Q, Nicoll RA (2001) Metabotropic glutamate receptor activation causes a rapid redistribution of AMPA receptors. Neuropharmacology 41:664-671.

Xu L, Anwyl R, Rowan MJ (1997) Behavioural stress facilitates the induction of long-term depression in the hippocampus. Nature 387:497-500.

Yang CH, Huang CC, Hsu KS (2005) Behavioral stress enhances hippocampal CA1 long-term depression through the blockade of the glutamate uptake. J Neurosci 25:4288-4293.

Yang L, Mao L, Tang Q, Samdani S, Liu Z, Wang JQ (2004) A novel Ca ${ }^{2+}$ independent signalling pathway to extracellular signal-regulated protein kinase by coactivation of NMDA receptors and mGluR5 in neurons. J Neurosci 24:10846-10857.

Zakharenko SS, Zablow L, Siegelbaum SA (2002) Altered presynaptic vesicle release and cycling during mGluR-dependent LTD. Neuron 35:1099-1110.

Zhang XL, Zhou ZY, Winterer J, Müller W, Stanton PK (2006) NMDAdependent, but not group I metabotropic glutamate receptor-dependent, long-term depression at Schaffer collateral-CA1 synapses is associated with long-term reduction of release from the rapidly recycling presynaptic vesicle pool. J Neurosci 26:10270-10280.

Zho WM, You JL, Huang CC, Hsu KS (2002) The group I metabotropic glutamate receptor agonist (S)-3,5-dihydroxyphenylglycine induces a novel form of depotentiation in the CAl region of the hippocampus. J Neurosci 22:8838-8849. 